ISSN 2072-6694

www.mdpi.com/journal/cancers

Review

\title{
Role of Met Axis in Head and Neck Cancer
}

\section{Yiru Xu * and Gary J. Fisher *}

Department of Dermatology, University of Michigan, Ann Arbor, MI 48109, USA

* Authors to whom correspondence should be addressed; E-Mails: xuyiru@umich.edu (Y.X.); dianemch@umich.edu (G.J.F.); Tel.: +1-734-763-1469 (G.J.F.); Fax: +1-734-647-0076 (G.J.F.).

Received: 15 October 2013; in revised form: 12 November 2013 / Accepted: 14 November 2013 / Published: 26 November 2013

\begin{abstract}
Head and neck cancer is the sixth most common type of cancer worldwide. Despite advances in aggressive multidisciplinary treatments, the 5-year survival rate for this dreadful disease is only $50 \%$, mostly due to high rate of recurrence and early involvement of regional lymph nodes and subsequent metastasis. Understanding the molecular mechanisms responsible for invasion and metastasis is one of the most pressing goals in the field of head and neck cancer. Met, also known as hepatocyte growth factor receptor (HGFR), is a member of the receptor protein tyrosine kinase (RPTK) family. There is compelling evidence that Met axis is dysregulated and plays important roles in tumorigenesis, progression, metastasis, angiogenesis, and drug resistance in head and neck cancer. We describe in this review current understanding of Met axis in head and neck cancer biology and development of therapeutic inhibitors targeting Met axis.
\end{abstract}

Keywords: head and neck cancer; receptor protein tyrosine kinase; hepatocyte growth factor receptor

\section{Introduction}

Cancer from the head and neck region is the sixth most common cancer and accounts for some 350,000 cancer deaths worldwide each year [1,2]. More than $90 \%$ of head and neck cancer is squamous cell carcinoma (HNSCC) originated from the squamous epithelium lining of upper aerodigestive tract. The most prominent contributors for the development of HNSCC include tobacco use, alcohol consumption, and human papillomavirus (HPV) infections [3,4]. High mortality rates and severe morbidity are two common features of HNSCC. HNSCC affects tongue, oral cavity, 
oropharynx, hypopharynx, larynx, and nasopharynx and thus compromises essential functions such as speech and swallowing. Close to half of HNSCC patients will die from their disease within five years [5]. Despite advances in aggressive multidisciplinary treatments during the last two decades, the 5-year survival rate for HNSCC has not improved significantly and is lower than that for other major cancer types such as lymphoma, breast cancer, and malignant melanoma [6].

Traditional treatment for HNSCC has been extensive surgery, which often yields a poor functional outcome. In recent years, improved therapy has been developed involving intensity-modulated radiation and concurrent use of chemotherapy [7]. In addition, advances have been made in elucidating molecular mechanisms and tumor biology that are important for the development and progression of HNSCC. Evidence demonstrates the importance of epidermal growth factor receptor (EGFR) tyrosine kinase signaling pathways in tumorigenesis and progression of HNSCC. This information has led to application of therapeutic strategies that target EGFR. Indeed, cetuximab, a monoclonal anti-epidermal growth factor receptor (EGFR) antibody, has been shown to improve median survival, when combined with cytotoxic chemotherapy in treatment of advanced HNSCC [8]. Hepatocyte growth factor receptor (HGFR, also known as Met) pathway, is another important growth factor pathway that has been shown to be important for the development of HNSCC. A growing body of evidence suggests that Met pathway could function as a driving force for invasive growth and early metastasis of HNSCC, and may cooperate with EGFR to cause resistance against anti-EGFR therapy. Therefore, Met is an attractive therapeutic target for treatment of HNSCC [9].

\section{The Met Signaling Pathway and Functions}

Hepatocyte growth factor (HGF), also known as scatter factor, is active in numerous tissues [10]. HGF is synthesized and secreted by mesenchymal cells as a $90-\mathrm{kDa}$ inactive single-chain polypeptide and then proteolytically cleaved into an active disulfide-linked heterodimer [11]. HGF participates in the regulation of organogenesis, tissue repair, angiogenesis and neural induction [11]. HGF is a unique growth factor that elicits multiple cellular responses. HGF is mitogenic in many normal cell types, including epithelial cells, vascular endothelial cells, and melanocytes. HGF can also function as a morphogen that induces transition of epithelial cells into a mesenchymal morphology and formation of branched tube-like structures [12,13]. HGF induces random movement/scattering in epithelial cells as well as dissociation, migration, and invasion of cells through the extracellular matrix in vivo $[14,15]$. HGF actions are mediated through binding to its specific cell surface receptor, Met. Activation of Met by HGF initiates various intracellular signal transduction cascades [16,17].

Met gene, located on chromosome 7q31, encodes a receptor protein tyrosine kinase (RPTK). Native Met protein is proteolytically processed to a heterodimer composed of a $50 \mathrm{kDa} \alpha$ subunit and a $145 \mathrm{kDa} \beta$ subunit, linked together by disulfide bonds [18]. In addition to the intracellular tyrosine kinase domain, Met also has several other function domains including an extracellular ligand-binding semaphorin (SEMA) domain, a transmembrane domain, and a regulatory juxtamembrane (JM) domain $[19,20]$. Like other RPTKs, ligand binding induces Met dimerization and trans-phosphorylation of several tyrosines within the $C$-terminal domain of the $\beta$ subunit, with concomitant activation of downstream effector molecules [15,21,22]. The function of Met is determined by these phosphorylated tyrosines, which serve as docking sites for signaling proteins [23,24]. Signaling proteins that are 
recruited to and activated in response to Met phosphorylation include: Akt, Cbl, Crk, cortactin, Erk, Fak, Gab1, Grb2, Jnk, paxillin, PI3 kinase, PLC- $\gamma$, Ras, Shc, Shp-2, Src, and STAT3 [15,25]. Among the tyrosines within the $C$-terminus, tyrosine residues 1234 and 1235 , located within the catalytic domain, are required for tyrosine kinase activity [26,27]. Tyrosines 1349 and 1356 compose multifunctional docking sites for Src homology 2 (SH2) domain-containing molecules such as Gab1, Grab2, PI3 kinase, and Cbl. Phosphorylation of these two tyrosines is necessary and sufficient for transmission of down-stream signaling events [28-30]. For example, binding of Grb2 to tyrosine 1356 results in activation of Ras-Raf-MAP kinase pathway and promotes cell proliferation [31]. Recruitment of Gab1 and its associations with Shp-2 and PLC- $\gamma$ results in HGF-induced branching morphogenetic activity [31,32].

\section{Regulation of Met Signaling Pathway}

\subsection{Positive Regulation}

CD44 is a cell surface adhesion molecule that is involved in cell-cell and cell-matrix interactions. A number of CD44 isoforms, which differ in their extracellular domain, can be generated via alternative splicing [33]. The extracellular domain of CD44v6, one of the CD44 isoform, participates in binding of HGF to Met and is required for activation of Met by HGF in epithelial cells [34]. In the absence of CD44v6, ICAM-1 can substitute for CD44v6 as a co-receptor for Met signaling, resulting in similar HGF-dependent c-Met pathway activation [35]. The cytoplasmic domain of CD44v6 is essential for efficient activation of Ras by promoting the assembly of signaling proteins including Grb2, SOS, F-actin, ezrin, radixin and moesin [36]. CD44v10, another CD44 isoform, has been reported to facilitate Met signaling in endothelial cells by providing structural and topographical support that facilitates HGF binding [37].

The extracellular domain of Met shares structural homology with plexins, which are transmembrane receptors for semaphorins. Semaphorins function to control axonal guidance in the nervous system. Plexins are also expressed in other tissues where Met is present [38]. The highly conserved cytoplasmic domain of plexins does not possess enzymatic activity, but is capable of interacting with small GTP-binding proteins to control cytoskeletal structures [39-41]. In the absence of HGF, Met can form complexes with plexins and can be stimulated by semaphorins, leading to activation of Met signaling pathway and biological responses $[42,43]$.

Although $\alpha 6 \beta 4$ integrin does not possess an intrinsic catalytic activity, it has been shown to promote invasive growth. $\alpha 6 \beta 4$ integrin physically interacts with Met and Met activation by HGF leads to tyrosine phosphorylation of the $\beta 4$-subunit cytoplasmic domain. The resultant phosphorylated tyrosines provide supplementary docking sites for the recruitment of PI3 kinase, Shc, and Shp2 [44,45]. For example, recruitment of adapter protein Shc to $\beta 4$ subunit cytoplasmic domain results in activation of Ras-MAPK pathway [46]. Although interaction between $\alpha 6 \beta 4$ integrin and Met does not affect Met tyrosine kinase activity or Met C-terminal tyrosine phosphorylation, these additional docking sites on $\alpha 6 \beta 4$ integrin cooperate with Met to potentiate activation of downstream pathways to achieve full scale Met-dependent responses and magnify Met biological functions. 
Several studies have demonstrated that Met can be trans-activated by other receptor protein tyrosine kinases (RTKs) [47]. For example, in the absence of HGF, ligand activation of EGFR can activate Met in cells that express both Met and EGFR [48]. Similarly, activation of RON RTK causes Met transactivation in a HGF-independent manner [49]. In addition, G-protein-coupled receptor agonists, such as bradykinin and thrombin, can induce Met activation via a reactive oxygen species-dependent mechanism [50], which likely involves inhibition of protein tyrosine phosphatase activity (see below).

\subsection{Negative Regulations of Met}

\subsubsection{Negative Regulation of Met by Protein Tyrosine Phosphatases (PTPs)}

Met plays important roles in both physiological and pathological conditions. The function of Met is determined by phosphorylation of $C$-terminal tyrosines, which serve as docking sites for down-stream signaling molecules. Therefore, tyrosine phosphorylation is synonymous with Met activation. Net tyrosine phosphorylate of Met is determined by dynamic equilibrium of intrinsic tyrosine kinase activity of Met and counteracting protein tyrosine phosphatases (PTPs). Several PTPs have been shown to regulate Met tyrosine phosphorylation. Palka et al. has demonstrated that DEP-1 (also known as RPTP-J) preferentially dephosphorylates tyrosines 1349 and 1365. However, DEP-1 does not appear to affect Met-mediated MAP kinase activation [51]. Antisense knockdown of RPTP-LAR has been shown to increases tyrosine phosphorylation of Met [52]. PTP1B and TCPTP have also been shown to dephosphorylate tyrosines $1234 / 1235$ of Met [53].

RPTP- $\beta$ regulation of Met tyrosine phosphorylation and biological functions has been extensively studied. Purified RPTP- $\beta$ directly dephosphorylates purified Met and substrate-trapping mutant of RPTP- $\beta$ specifically interacts with Met in intact cells. In addition, expression of RPTP- $\beta$ reduces both basal and HGF-induced Met phosphorylation at tyrosine 1356 and inhibits downstream MEK1/2 and Erk activation, while shRNA-mediated knockdown of RPTP- $\beta$ increases basal and HGF-stimulated Met phosphorylation at tyrosine 1356 [54]. Furthermore, expression of RPTP- $\beta$ in HNSCC cells decreased Met tyrosine phosphorylation, downstream signaling, and HGF-induced responses including cell proliferation, migration and invasion. Knockdown of RPTP- $\beta$ in HNSCC cells enhanced these functions [55].

Normal epithelial cells express Met, but not HGF [19]. HGF is secreted by stromal cells to activate Met, in a paracrine fashion. Completion of an autocrine loop by expression of HGF in epithelial cells, or overexpression of Met leads to transformation [56,57]. Down-regulation of RPTP- $\beta$, with or without increased expression of Met, would be expected to result in activation of the Met pathway [55].

\subsubsection{Negative Regulation of Met by Receptor Endocytosis}

Met internalization is a major negative regulatory mechanism for desensitizing Met signaling pathway. HGF-induced endocytosis of Met, terminates signaling by sequestering Met in lysosomes, where it is degradated and prevented from recycling to the plasma membrane. Tyrosine 1003, located in the juxtamembrane domain of ligand-activated Met, recruits E3 ubiquitin ligase Cbl, resulting in mono-ubiquitination of Met at multiple sites [58]. Ubiquitylated Met is then recognized by endocytic 
adaptors that contain ubiquitin-binding domains and targets Met to the endosomal network for sequestration and degradation $[59,60]$.

\subsubsection{Other Negative Regulatory Mechanisms}

Under steady-state conditions, Met is also subjected to low level of proteolytic cleavage independent of ligand or ubiquitination. The $N$-terminal extracellular domain is first cleaved by a disintegrin and metalloprotease (ADAM), resulting in a membrane-anchored cytoplasmic tail. The membrane-associated cytoplasmic region is further processed by $\gamma$-secretase mediated proteolysis into labile intracellular fragments for ultimate degradation by proteosomes [61].

In addition, LRIG1, a transmembrane leucine-rich repeat and immunoglobulin (Ig)-like domain-containing protein, interacts with Met and negatively affect Met protein stability in HGF and $\mathrm{Cbl}$ independent manner, thereby, negatively regulating Met function [62].

miRNAs are small noncoding endogenous RNAs that can negatively regulate protein expression by targeting transcripts for degradation and by blocking translation [63]. A number of miRNAs have been demonstrated to down-regulate MET protein expression, including miR-133b, miR-199*, miR-34b, miR-34c, miR-23b, and miR-198 [64-67].

\section{The Role of Met in Cancer Progression and Metastasis}

In addition to its key participation in many physiological processes, numerous in vivo and in vitro studies point toward the importance of Met in human malignancy. Stimulation of Met by HGF enhances cell proliferation, survival, dissociation, migration, morphogenesis, formation of blood vessels, and degradation of extracellular matrix, all characteristics that are associated with invasive cell phenotype [68]. Met pathway also plays key roles in epithelial-mesenchymal transition, which is involved in tumor invasion [11]. Many types of cancer exhibit sustained Met tyrosine phosphorylation, including carcinomas of the head and neck, breast, colon, kidney, liver, lung, ovary, prostate, thyroid, melanoma, and sarcoma [69-71].

Aberrant Met signaling can be achieved by Met or HGF gene over-expression, Met point mutations, amplification, or gene rearrangement, leading to constitutive tyrosine kinase activity. Met was originally isolated as TPR-Met oncogene, which possesses ligand-independent tyrosine kinase activity, due to chromosomal rearrangement of translocated promoter region (TPR) in chromosome 1 fused to Met $C$-terminal sequence in chromosome $7[17,72]$. This rearrangement was later confirmed in patients with gastric carcinoma [73].

Met point mutations have been identified in hereditary and sporadic papillary renal carcinoma, hepatocellular and gastric carcinomas and head and neck squamous cell carcinomas [74]. Large body of literature shows that aberrant regulation of HGF/Met signaling pathway is involved in many types of human cancers. Inappropriate expression of HGF/Met autocrine signaling leads to increased tumorigenesis and enhanced metastatic activity [57]. Met expression is strongly associated with tumor metastasis and correlates with poor prognosis $[15,75,76]$.

Met can also be responsible for resistance of tumors against therapies. For example, in the presence of EGFR inhibitors, such as gefitinib, a subset of tumor cells with high Met expression (i.e., with Met gene amplification) can escape EGFR inhibition. These cells become resistant to anti-EGFR therapy 
and can undergo rapid clonal expansion [77]. These findings have led to the proposal that EGFR and Met inhibitors should be used simultaneously to treat certain cancers [78-80].

\section{Met Axis in Head and Neck Cancer}

\subsection{Over-Activation of Met Axis in HNSCC}

Over-expression of Met has been reported in nearly all types of HNSCC, including cancer of the hypopharynx, larynx, and oral cavity. This over-expression often correlates with more advanced clinical stages especially the nodal stage [81-84]. Knowles and colleagues reported that approximately $80 \%$ of primary HNSCC tumors display abnormal expression of HGF, Met or both [85]. Cortesina et al. reported that Met was over-expressed in most HNSCC specimens they analyzed [86] and Galeazzi et al. reported that Met over-expression was detected in 70\% of HNSCC samples they tested, even more so in lymph node metastases [87]. Expression of Met and/or its ligand HGF increases during progression of HNSCC and there is a substantial increase of Met levels in affected lymph nodes, compared to corresponding primary tumors [82-84,87,88]. High Met expression is significantly correlated with reduced patient survival rate because these patients are more likely to have local recurrences and are more likely to develop distant metastases [89]. Patients with higher Met expression also have inferior response to both radiotherapy and chemotherapy [90,91]. In addition, elevated serum levels of HGF are significantly associated with advanced tumor metastasis stage and poor survival in HNSCC [92]. Increased expression of HGF has also been positively linked to lymph node metastasis of HNSCC in vivo [81,82,93].

Consistent with in vivo data, HGF stimulation of Met-expressing HNSCC cell lines promotes an invasive phenotype [15,94]. Furthermore, activating mutations of Met are specifically selected during HNSCC metastasis [95]. Transcripts of these mutant alleles are highly represented in metastases, but barely detectable in primary tumors, suggesting that cells carrying these Met mutations have growth advantage and are selected during clonal expansion and metastatic spreading. Genetic transfer of mutant Met to HNSCC cells confers invasive phenotype [95]. Interestingly, RPTP- $\beta$, a major negative regulator of Met phosphorylation and function in HNSCC, is significantly down-regulated in metastatic tumors in comparison with primary tumors [55]. Taken together, there exists compelling evidence that points to the importance of Met axis in metastasis of HNSCC.

\subsection{Met in HNSCC Progression}

HNSCC metastasis is a multi-stage process that includes cellular detachment, epithelial-mesenchymal transition, proteolytic degradation of the basement membrane, migration through extracellular matrix, resistance to apoptosis in a new environment, and formation of new blood vessels [74]. Activation of Met signaling pathway drives cancer cells to acquire an invasive growth phenotype and promotes each of the stages of HNSCC metastasis.

E-cadherin is an important cell adhesion molecule in epithelial cells and disruption of E-cadherin mediated cell-to-cell adhesion promotes detachment of cancer cells from their primary sites [96], which is the first step in tumor invasion process. Activation of Met by HGF in HNSCC cell lines decreases E-cadherin expression and induces E-cadherin translocation from the cell surface membrane 
to the cytoplasm [97]. HGF up-regulates transcription factor Snail via MAP kinase and Egr-1 signaling pathways in HNSCC cell lines [98]. HGF-induced Snail expression not only suppresses E-cadherin expression, but also promotes epithelial-mesenchymal transition, a process that allows epithelial cells to gain a fibroblast-like phenotype that is essential for tumor invasion [99-101].

Activation of Met by HGF in HNSCC cells leads to activation of Erk and Akt kinases, and Ets-related transcription factor E1AF activation, which in turn results in up-regulation of urokinase-type plasminogen activator and matrix metalloproteinases (MMP-1, 3 and 9) production [94,102]. These proteases are capable of degrading the extracellular matrix and may cooperate with MT-MMP-1 to facilitate cell migration through basement membrane, a critical step in tumor invasion. Met activation enhances HNSCC cell migration through mechanisms that involve Ras-related small G-protein Rho, and focal adhesion kinase [103,104]. Activation of Erk and Akt kinases by HGF promotes cell survival by protection against cell death that results from detachment from the extracellular matrix (anoikis) [105].

Higher serum HGF levels correlate with higher levels of angiogenic factors such as interleukin-8 (IL-8) and vascular endothelial growth factor (VEGF) in patients with HNSCC [106]. In vitro experiment showed that HGF treatment of HNSCC cells increased IL-8 and VEGF production [107]. Furthermore, HNSCC cells from tumors that are enriched in Met positive cells are able to form spherical colonies in anchorage-independent culture condition and are capable of self-renewal. These Met enriched cells are able to recapitulate the heterogeneity of the parental tumors in vitro and in vivo. This capability is further enhanced by the presence of CD44 which facilitates Met activation. In addition, these Met positive cells have enhanced metastatic ability and are resistant to cisplatin treatment [108].

\subsection{Met in Resistance to HNSCC Therapy}

EGFR is over-expressed in over 80\% of HNSCC tumors [109] and anti-EGFR therapies using EGFR tyrosine kinase inhibitors (TKIs) or EGFR neutralizing antibodies have been used in combination with radiation therapy and chemotherapy against HNSCC [110]. Met signaling pathway induces invasive tumor growth and shares many components and mechanisms with EGFR signaling pathway [111]. Therefore, the Met axis may substitute and bypass EGFR functions when EGFR is inhibited by anti-EGFR therapies [112,113]. Indeed, over-activation of Met has been reported to correlate with resistance to EGFR neutralizing antibody cetuximab and other EGFR inhibitors in HNSCC cell lines [9]. Stabilization of Met in HNSCC cell lines by over-expression of cortactin, a key regulator of dynamic actin networks and modulator of receptors signaling, increases Met activity and resistance to EGFR tyrosine kinase inhibitor gefitinib [114]. Furthermore, low expression of Met is a predictive factor for a positive response in HNSCC patients treated with chemotherapy [91]. Ligand-independent activation of Met pathway by activated c-Src in HNSCC cells provides an alternate survival pathway and contributes to erlotinib resistance [115]. 


\section{Targeting the MET Axis in HNSCC:}

\subsection{Cancer Drugs Targeting Met Pathway}

In view of its high expression in various human malignancies and its involvement in mediating invasive growth of many types of cancers, Met has been identified as an attractive target for cancer treatment. Many types of inhibitors have been developed to inhibit this signaling pathway, including receptor antagonists, small-molecule tyrosine kinase inhibitors (TKIs), and monoclonal antibodies (mAbs). Among them, mAbs such as rilotumumab and onartuzumab, and TKIs such as tivantinib, crizotinib, foretinib and cabozantinib have recently been tested in phase I and II clinical trials [9].

NK4 is a receptor antagonist consisting of $N$-terminal 4 kringle domains of the $\alpha$-chain of HGF. NK4 competes with HGF binding to Met, thereby inhibits HGF-dependent Met tyrosine phosphorylation, down-stream signal pathways, cell proliferation, and invasion [116-118]. In addition, NK4 inhibits VEGF and basic FGF induced angiogenesis independent of its HGF-antagonist function [117]. No clinical trial has been initiated with this anti-Met reagent.

Rilotumumab (also known as AMG102), is a humanized monoclonal antibody that selectively binds and neutralizes HGF, thereby preventing HGF binding to Met and interfering with Met activation $[119,120]$. An acceptable safety profile was shown in phase I and II clinical trials with mild side effects such as fatigue and gastrointestinal symptoms [121,122]. In advanced or metastatic gastric or gastroesophageal cancers, which have high Met protein expression, treatment with rilotumumab in combination with chemotherapy improves progression-free survival [123].

Onartuzumab is a humanized mono-valent anti-Met antibody (OA5D5/MetMAb). It binds Met with high affinity, thereby preventing HGF binding to Met and consequent Met phosphorylation, and activation of downstream signaling events. In preclinical studies, onartuzumab has been shown to inhibit tumor growth in multiple tumor models [124,125]. Onartuzumab is currently in a randomized, multi-center, double-blind human phase III clinical trial to evaluate its efficacy and safety in gastric cancer (ClinicalTrials.gov Identifier: NCT01662869).

Tivantinib (ARQ197) is a non-competitive, ATP-site selective, small molecule inhibitor of Met tyrosine kinase [126]. Phase I trials have shown a favorable safety profile and preliminary results suggest potential anti-invasive activity for this compound in advanced solid tumors [127]. Tivantinib is currently in phase II clinical trial.

Cabozantinib (formerly known as XL184) is another multi-kinase inhibitor against Met, VEGFR2, and Ret. Phase I and II studies have shown promising results for improvement on patient survival [128]. A randomized phase III trial of cabozantinib in thyroid cancer has been initiated (clinicaltrials.gov Identifier: NCT00704730).

\subsection{Targeting Met Axis in HNSCC Cells and HNSCC Patients}

Met targeted therapy is a relatively new area of clinical investigation in HNSCC treatment. Met pathway inhibitors might be used in combination with chemotherapy, radiotherapy, or immunotherapy reagents to overcome potential tumor resistance and to improve overall clinical outcome. Several clinical trials are ongoing to investigate the effects of monoclonal antibodies and small molecular TKI against Met axis in patients with recurrent HNSCC. 
Crizotinib (PF-02341066) is a potent and selective dual specific TKI for both Met and ALK. It exhibits inhibitory effects on Met-dependent proliferation, migration, and invasion of human tumor cells and is also effective against tumors with an activating ALK gene rearrangement [129]. In a preclinical HNSCC xenograft mouse model, crizotinib was shown to decrease tumor proliferation and increase apoptosis within the tumors, and delay HNSCC tumor growth by 50\% [85]. Crizotinib has also been shown to suppress Met signaling, cell viability, and migration in HNSCC cells, and tumor angiogenesis in a HNSCC xenograft model [79]. Furthermore, combination treatment of crizotinib and EGFR inhibitor gefitinib disrupts cell proliferation and invasion significantly more than inhibition of each pathway alone in HNSCC cell lines [130]. These results suggest that anti-Met therapy has the potential to improve outcomes in HNSCC patients.

Foretinib (formerly known as XL880) is a multi-targeted TKI whose primary targets are Met and VEGF [131]. It is the first orally bio-available small molecule targeting Met. A Phase II clinical trial of foretinib in HNSCC has been completed but the results have not been posted yet (clinicaltrials.gov Identifier: NCT00725764). LY2801653 is another orally bio-available multi-targeted TKI against Met and MST1R. It has been demonstrated to exhibit anti-tumor activities in mouse xenograft models in a preclinical study [132]. A Phase I Study of LY2801653 in patients with HNSCC is currently ongoing but no results are available (clinicaltrials.gov Identifier: NCT01285037).

\section{Perspective and Conclusions}

Since the discovery of Met more than 25 years ago, much has been learned about its roles in a broad spectrum of cellular and biological functions, including mitogenesis, morphogenesis, angiogenesis, migration, and invasiveness. While these biological processes are tightly regulated during embryogenesis, tissue homeostasis in adulthood, wound healing, and liver regeneration, aberrant activation of Met by gene amplification, gene re-arrangement, point mutations, protein over-expression, or loss of negative regulatory mechanisms can contribute to tumor initiation, progression, metastasis and resistance to therapy. Therefore, Met axis is an attractive target for cancer treatment and a number of Met pathway inhibitors have been developed and are currently in clinical trials. Anti-Met clinical studies for HNSCC are ongoing and results from these studies will shape the landscape for future use of Met inhibitors in HNSCC. Further clinical trials on the efficacy of Met inhibition in HNSCC and other types of solid tumors are warranted, given the important role of Met axis in HNSCC invasive growth.

\section{Acknowledgments}

We thank Diane Fiolek for administrative assistance. This work was supported by a grant from the NIH (RO1-ES-012920 to G.J.F. and Y.X.).

\section{Conflicts of Interest}

The authors declare no conflict of interest. 


\section{References}

1. Jemal, A.; Siegel, R.; Ward, E.; Hao, Y.; Xu, J.; Murray, T.; Thun, M.J. Cancer statistics, 2008. CA Cancer J. Clin. 2008, 58, 71-96.

2. Parkin, D.M.; Bray, F.; Ferlay, J.; Pisani, P. Global cancer statistics, 2002. CA Cancer J. Clin. 2005, 55, 74-108.

3. Argiris, A.; Eng, C. Epidemiology, staging, and screening of head and neck cancer. Cancer Treat. Res. 2003, 114, 15-60.

4. D’Souza, G.; Kreimer, A.R.; Viscidi, R.; Pawlita, M.; Fakhry, C.; Koch, W.M.; Westra, W.H.; Gillison, M.L. Case-control study of human papillomavirus and oropharyngeal cancer. N. Engl. J. Med. 2007, 356, 1944-1956.

5. Haddad, R.I.; Shin, D.M. Recent advances in head and neck cancer. N. Engl. J. Med. 2008, 359, $1143-1154$.

6. Lothaire, P.; de Azambuja, E.; Dequanter, D.; Lalami, Y.; Sotiriou, C.; Andry, G.; Castro, G., Jr.; Awada, A. Molecular markers of head and neck squamous cell carcinoma: Promising signs in need of prospective evaluation. Head Neck 2006, 28, 256-269.

7. Murdoch, D. Standard, and novel cytotoxic and molecular-targeted, therapies for hnscc: An evidence-based review. Curr. Opin. Oncol. 2007, 19, 216-221.

8. Vermorken, J.B.; Mesia, R.; Rivera, F.; Remenar, E.; Kawecki, A.; Rottey, S.; Erfan, J.; Zabolotnyy, D.; Kienzer, H.R.; Cupissol, D.; et al. Platinum-based chemotherapy plus cetuximab in head and neck cancer. N. Engl. J. Med. 2008, 359, 1116-1127.

9. Lau, P.C.; Chan, A.T. Novel therapeutic target for head and neck squamous cell carcinoma: Hgf-met signaling pathway. Anticancer Drugs 2011, 22, 665-673.

10. Nakamura, T.; Nishizawa, T.; Hagiya, M.; Seki, T.; Shimonishi, M.; Sugimura, A.; Tashiro, K.; Shimizu, S. Molecular cloning and expression of human hepatocyte growth factor. Nature 1989, 342, 440-443.

11. Birchmeier, C.; Birchmeier, W.; Gherardi, E.; vande Woude, G.F. Met, metastasis, motility and more. Nat. Rev. Mol. Cell Biol. 2003, 4, 915-925.

12. Soriano, J.V.; Pepper, M.S.; Nakamura, T.; Orci, L.; Montesano, R. Hepatocyte growth factor stimulates extensive development of branching duct-like structures by cloned mammary gland epithelial cells. J. Cell Sci. 1995, 108, 413-430.

13. Weidner, K.M.; Sachs, M.; Birchmeier, W. The met receptor tyrosine kinase transduces motility, proliferation, and morphogenic signals of scatter factor/hepatocyte growth factor in epithelial cells. J. Cell Biol. 1993, 121, 145-154.

14. Gentile, A.; Trusolino, L.; Comoglio, P.M. The met tyrosine kinase receptor in development and cancer. Cancer Metastasis Rev. 2008, 27, 85-94.

15. Peschard, P.; Park, M. From tpr-met to met, tumorigenesis and tubes. Oncogene 2007, 26, 1276-1285.

16. Bottaro, D.P.; Rubin, J.S.; Faletto, D.L.; Chan, A.M.; Kmiecik, T.E.; vande Woude, G.F.; Aaronson, S.A. Identification of the hepatocyte growth factor receptor as the c-met proto-oncogene product. Science 1991, 251, 802-804. 
17. Cooper, C.S.; Park, M.; Blair, D.G.; Tainsky, M.A.; Huebner, K.; Croce, C.M.; vande Woude, G.F. Molecular cloning of a new transforming gene from a chemically transformed human cell line. Nature 1984, 311, 29-33.

18. Trusolino, L.; Bertotti, A.; Comoglio, P.M. Met signalling: Principles and functions in development, organ regeneration and cancer. Nat. Rev. Mol. Cell Biol. 2010, 11, 834-848.

19. Ma, P.C.; Maulik, G.; Christensen, J.; Salgia, R. C-met: Structure, functions and potential for therapeutic inhibition. Cancer Metastasis Rev. 2003, 22, 309-325.

20. Peruzzi, B.; Bottaro, D.P. Targeting the c-met signaling pathway in cancer. Clin. Cancer Res. 2006, 12, 3657-3660.

21. Rubin, J.S.; Bottaro, D.P.; Aaronson, S.A. Hepatocyte growth factor/scatter factor and its receptor, the c-met proto-oncogene product. Biochim. Biophys. Acta 1993, 1155, 357-371.

22. Stuart, K.A.; Riordan, S.M.; Lidder, S.; Crostella, L.; Williams, R.; Skouteris, G.G. Hepatocyte growth factor/scatter factor-induced intracellular signalling. Int. J. Exp. Pathol. 2000, 81, 17-30.

23. Komada, M.; Kitamura, N. The cell dissociation and motility triggered by scatter factor/hepatocyte growth factor are mediated through the cytoplasmic domain of the c-met receptor. Oncogene 1993, 8, 2381-2390.

24. Naldini, L.; Vigna, E.; Ferracini, R.; Longati, P.; Gandino, L.; Prat, M.; Comoglio, P.M. The tyrosine kinase encoded by the met proto-oncogene is activated by autophosphorylation. Mol. Cell Biol. 1991, 11, 1793-1803.

25. Bolanos-Garcia, V.M. Met meet adaptors: Functional and structural implications in downstream signalling mediated by the met receptor. Mol. Cell Biochem 2005, 276, 149-157.

26. Ferracini, R.; Longati, P.; Naldini, L.; Vigna, E.; Comoglio, P.M. Identification of the major autophosphorylation site of the met/hepatocyte growth factor receptor tyrosine kinase. J. Biol. Chem. 1991, 266, 19558-19564.

27. Longati, P.; Bardelli, A.; Ponzetto, C.; Naldini, L.; Comoglio, P.M. Tyrosines1234-1235 are critical for activation of the tyrosine kinase encoded by the met proto-oncogene (hgf receptor). Oncogene 1994, 9, 49-57.

28. Fixman, E.D.; Naujokas, M.A.; Rodrigues, G.A.; Moran, M.F.; Park, M. Efficient cell transformation by the tpr-met oncoprotein is dependent upon tyrosine 489 in the carboxy-terminus. Oncogene 1995, 10, 237-249.

29. Ponzetto, C.; Bardelli, A.; Zhen, Z.; Maina, F.; dalla Zonca, P.; Giordano, S.; Graziani, A.; Panayotou, G.; Comoglio, P.M. A multifunctional docking site mediates signaling and transformation by the hepatocyte growth factor/scatter factor receptor family. Cell 1994, 77, 261-271.

30. Zhu, H.; Naujokas, M.A.; Fixman, E.D.; Torossian, K.; Park, M. Tyrosine 1356 in the carboxyl-terminal tail of the hgf/sf receptor is essential for the transduction of signals for cell motility and morphogenesis. J. Biol. Chem. 1994, 269, 29943-29948.

31. Schaeper, U.; Gehring, N.H.; Fuchs, K.P.; Sachs, M.; Kempkes, B.; Birchmeier, W. Coupling of gab1 to c-met, grb2, and shp2 mediates biological responses. J. Cell Biol. 2000, 149, 1419-1432.

32. Gual, P.; Giordano, S.; Williams, T.A.; Rocchi, S.; van Obberghen, E.; Comoglio, P.M. Sustained recruitment of phospholipase c-gamma to gab1 is required for hgf-induced branching tubulogenesis. Oncogene 2000, 19, 1509-1518. 
33. Ponta, H.; Sherman, L.; Herrlich, P.A. Cd44: From adhesion molecules to signalling regulators. Nat. Rev. Mol. Cell Biol 2003, 4, 33-45.

34. Orian-Rousseau, V.; Chen, L.; Sleeman, J.P.; Herrlich, P.; Ponta, H. Cd44 is required for two consecutive steps in hgf/c-met signaling. Genes Dev. 2002, 16, 3074-3086.

35. Olaku, V.; Matzke, A.; Mitchell, C.; Hasenauer, S.; Sakkaravarthi, A.; Pace, G.; Ponta, H.; Orian-Rousseau, V. $C$-met recruits icam-1 as a coreceptor to compensate for the loss of cd44 in cd44 null mice. Mol. Biol. Cell 2011, 22, 2777-2786.

36. Orian-Rousseau, V.; Morrison, H.; Matzke, A.; Kastilan, T.; Pace, G.; Herrlich, P.; Ponta, H. Hepatocyte growth factor-induced ras activation requires erm proteins linked to both cd44v6 and f-actin. Mol. Biol. Cell 2007, 18, 76-83.

37. Singleton, P.A.; Salgia, R.; Moreno-Vinasco, L.; Moitra, J.; Sammani, S.; Mirzapoiazova, T.; Garcia, J.G. Cd44 regulates hepatocyte growth factor-mediated vascular integrity. Role of c-met, tiam1/rac1, dynamin 2, and cortactin. J. Biol. Chem. 2007, 282, 30643-30657.

38. Raper, J.A. Semaphorins and their receptors in vertebrates and invertebrates. Curr. Opin. Neurobiol. 2000, 10, 88-94.

39. Driessens, M.H.; Hu, H.; Nobes, C.D.; Self, A.; Jordens, I.; Goodman, C.S.; Hall, A. Plexin-b semaphorin receptors interact directly with active rac and regulate the actin cytoskeleton by activating rho. Curr. Biol. 2001, 11, 339-344.

40. Perrot, V.; Vazquez-Prado, J.; Gutkind, J.S. Plexin b regulates rho through the guanine nucleotide exchange factors leukemia-associated rho gef (larg) and pdz-rhogef. J. Biol. Chem. 2002, 277, 43115-43120.

41. Vikis, H.G.; Li, W.; He, Z.; Guan, K.L. The semaphorin receptor plexin-b1 specifically interacts with active rac in a ligand-dependent manner. Proc. Natl. Acad. Sci. USA 2000, 97, 12457-12462.

42. Conrotto, P.; Corso, S.; Gamberini, S.; Comoglio, P.M.; Giordano, S. Interplay between scatter factor receptors and b plexins controls invasive growth. Oncogene 2004, 23, 5131-5137.

43. Hu, B.; Guo, P.; Bar-Joseph, I.; Imanishi, Y.; Jarzynka, M.J.; Bogler, O.; Mikkelsen, T.; Hirose, T.; Nishikawa, R.; Cheng, S.Y. Neuropilin-1 promotes human glioma progression through potentiating the activity of the hgf/sf autocrine pathway. Oncogene 2007, 26, 5577-5586.

44. Bertotti, A.; Comoglio, P.M.; Trusolino, L. Beta4 integrin is a transforming molecule that unleashes met tyrosine kinase tumorigenesis. Cancer Res. 2005, 65, 10674-10679.

45. Trusolino, L.; Bertotti, A.; Comoglio, P.M. A signaling adapter function for alpha6beta4 integrin in the control of hgf-dependent invasive growth. Cell 2001, 107, 643-654.

46. Mainiero, F.; Murgia, C.; Wary, K.K.; Curatola, A.M.; Pepe, A.; Blumemberg, M.; Westwick, J.K.; Der, C.J.; Giancotti, F.G. The coupling of alpha6beta4 integrin to ras-map kinase pathways mediated by shc controls keratinocyte proliferation. EMBO J. 1997, 16, 2365-2375.

47. Lai, A.Z.; Abella, J.V.; Park, M. Crosstalk in met receptor oncogenesis. Trends Cell Biol. 2009, 19, 542-551.

48. Jo, M.; Stolz, D.B.; Esplen, J.E.; Dorko, K.; Michalopoulos, G.K.; Strom, S.C. Cross-talk between epidermal growth factor receptor and c-met signal pathways in transformed cells. J. Biol. Chem. 2000, 275, 8806-8811.

49. Follenzi, A.; Bakovic, S.; Gual, P.; Stella, M.C.; Longati, P.; Comoglio, P.M. Cross-talk between the proto-oncogenes met and ron. Oncogene 2000, 19, 3041-3049. 
50. Fischer, O.M.; Giordano, S.; Comoglio, P.M.; Ullrich, A. Reactive oxygen species mediate met receptor transactivation by g protein-coupled receptors and the epidermal growth factor receptor in human carcinoma cells. J. Biol. Chem. 2004, 279, 28970-28978.

51. Palka, H.L.; Park, M.; Tonks, N.K. Hepatocyte growth factor receptor tyrosine kinase met is a substrate of the receptor protein-tyrosine phosphatase dep-1. J. Biol. Chem. 2003, 278, 5728-5735.

52. Machide, M.; Hashigasako, A.; Matsumoto, K.; Nakamura, T. Contact inhibition of hepatocyte growth regulated by functional association of the c-met/hepatocyte growth factor receptor and lar protein-tyrosine phosphatase. J. Biol. Chem. 2006, 281, 8765-8772.

53. Sangwan, V.; Paliouras, G.N.; Abella, J.V.; Dube, N.; Monast, A.; Tremblay, M.L.; Park, M. Regulation of the met receptor-tyrosine kinase by the protein-tyrosine phosphatase $1 \mathrm{~b}$ and $\mathrm{t}$-cell phosphatase. J. Biol. Chem. 2008, 283, 34374-34383.

54. Xu, Y.; Xia, W.; Baker, D.; Zhou, J.; Cha, H.C.; Voorhees, J.J.; Fisher, G.J. Receptor-type protein tyrosine phosphatase beta (rptp-beta) directly dephosphorylates and regulates hepatocyte growth factor receptor (hgfr/met) function. J. Biol. Chem. 2011, 286, 15980-15988.

55. Xu, Y.; Zhou, J.; Carey, T.E.; McHugh, J.B.; Voorhees, J.J.; Fisher, G.J. Receptor-type protein tyrosine phosphatase beta regulates met phosphorylation and function in head and neck squamous cell carcinoma. Neoplasia 2012, 14, 1015-1022.

56. Horiguchi, N.; Takayama, H.; Toyoda, M.; Otsuka, T.; Fukusato, T.; Merlino, G.; Takagi, H.; Mori, M. Hepatocyte growth factor promotes hepatocarcinogenesis through c-met autocrine activation and enhanced angiogenesis in transgenic mice treated with diethylnitrosamine. Oncogene 2002, 21, 1791-1799.

57. Otsuka, T.; Takayama, H.; Sharp, R.; Celli, G.; LaRochelle, W.J.; Bottaro, D.P.; Ellmore, N.; Vieira, W.; Owens, J.W.; Anver, M.; et al. C-met autocrine activation induces development of malignant melanoma and acquisition of the metastatic phenotype. Cancer Res. 1998, 58, 5157-5167.

58. Carter, S.; Urbe, S.; Clague, M.J. The met receptor degradation pathway: Requirement for lys48-linked polyubiquitin independent of proteasome activity. J. Biol. Chem. 2004, 279, 52835-52839.

59. Peschard, P.; Fournier, T.M.; Lamorte, L.; Naujokas, M.A.; Band, H.; Langdon, W.Y.; Park, M. Mutation of the c-cbl tkb domain binding site on the met receptor tyrosine kinase converts it into a transforming protein. Mol. Cell 2001, 8, 995-1004.

60. Petrelli, A.; Gilestro, G.F.; Lanzardo, S.; Comoglio, P.M.; Migone, N.; Giordano, S. The endophilin-cin85-cbl complex mediates ligand-dependent downregulation of c-met. Nature 2002, 416, 187-190.

61. Foveau, B.; Ancot, F.; Leroy, C.; Petrelli, A.; Reiss, K.; Vingtdeux, V.; Giordano, S.; Fafeur, V.; Tulasne, D. Down-regulation of the met receptor tyrosine kinase by presenilin-dependent regulated intramembrane proteolysis. Mol. Biol. Cell 2009, 20, 2495-2507.

62. Shattuck, D.L.; Miller, J.K.; Laederich, M.; Funes, M.; Petersen, H.; Carraway, K.L., 3rd; Sweeney, C. Lrig1 is a novel negative regulator of the met receptor and opposes met and her2 synergy. Mol. Cell Biol. 2007, 27, 1934-1946.

63. Garofalo, M.; Croce, C.M. Micrornas: Master regulators as potential therapeutics in cancer. Annu. Rev. Pharmacol. Toxicol. 2011, 51, 25-43. 
64. Hu, G.; Chen, D.; Li, X.; Yang, K.; Wang, H.; Wu, W. Mir-133b regulates the met proto-oncogene and inhibits the growth of colorectal cancer cells in vitro and in vivo. Cancer Biol. Ther. 2010, 10, 190-197.

65. Kim, S.; Lee, U.J.; Kim, M.N.; Lee, E.J.; Kim, J.Y.; Lee, M.Y.; Choung, S.; Kim, Y.J.; Choi, Y.C. Microrna mir-199a* regulates the met proto-oncogene and the downstream extracellular signal-regulated kinase 2 (erk2). J. Biol. Chem. 2008, 283, 18158-18166.

66. Migliore, C.; Petrelli, A.; Ghiso, E.; Corso, S.; Capparuccia, L.; Eramo, A.; Comoglio, P.M.; Giordano, S. Micrornas impair met-mediated invasive growth. Cancer Res. 2008, 68, 10128-10136.

67. Salvi, A.; Sabelli, C.; Moncini, S.; Venturin, M.; Arici, B.; Riva, P.; Portolani, N.; Giulini, S.M.; de Petro, G.; Barlati, S. Microrna-23b mediates urokinase and c-met downmodulation and a decreased migration of human hepatocellular carcinoma cells. FEBS J. 2009, 276, 2966-2982.

68. Lesko, E.; Majka, M. The biological role of hgf-met axis in tumor growth and development of metastasis. Front. Biosci. 2008, 13, 1271-1280.

69. Gherardi, E.; Birchmeier, W.; Birchmeier, C.; vande Woude, G. Targeting met in cancer: Rationale and progress. Nat. Rev. Cancer 2012, 12, 89-103.

70. Ma, P.C.; Tretiakova, M.S.; MacKinnon, A.C.; Ramnath, N.; Johnson, C.; Dietrich, S.; Seiwert, T.; Christensen, J.G.; Jagadeeswaran, R.; Krausz, T.; et al. Expression and mutational analysis of met in human solid cancers. Genes Chromosomes Cancer 2008, 47, 1025-1037.

71. Samame Perez-Vargas, J.C.; Biondani, P.; Maggi, C.; Gariboldi, M.; Gloghini, A.; Inno, A.; Volpi, C.C.; Gualeni, A.V.; di Bartolomeo, M.; de Braud, F.; et al. Role of cmet in the development and progression of colorectal cancer. Int. J. Mol. Sci. 2013, 14, 18056-18077.

72. Park, M.; Dean, M.; Kaul, K.; Braun, M.J.; Gonda, M.A.; vande Woude, G. Sequence of met protooncogene cdna has features characteristic of the tyrosine kinase family of growth-factor receptors. Proc. Natl. Acad. Sci. USA 1987, 84, 6379-6383.

73. Yu, J.; Miehlke, S.; Ebert, M.P.; Hoffmann, J.; Breidert, M.; Alpen, B.; Starzynska, T.; Stolte, M.; Malfertheiner, P.; Bayerdorffer, E. Frequency of tpr-met rearrangement in patients with gastric carcinoma and in first-degree relatives. Cancer 2000, 88, 1801-1806.

74. Trusolino, L.; Comoglio, P.M. Scatter-factor and semaphorin receptors: Cell signalling for invasive growth. Nat. Rev. Cancer 2002, 2, 289-300.

75. Jeffers, M.; Rong, S.; Woude, G.F. Hepatocyte growth factor/scatter factor-met signaling in tumorigenicity and invasion/metastasis. J. Mol. Med. 1996, 74, 505-513.

76. Mazzone, M.; Comoglio, P.M. The met pathway: Master switch and drug target in cancer progression. FASEB J. 2006, 20, 1611-1621.

77. Engelman, J.A.; Zejnullahu, K.; Mitsudomi, T.; Song, Y.; Hyland, C.; Park, J.O.; Lindeman, N.; Gale, C.M.; Zhao, X.; Christensen, J.; et al. Met amplification leads to gefitinib resistance in lung cancer by activating erbb3 signaling. Science 2007, 316, 1039-1043.

78. Chen, G.; Noor, A.; Kronenberger, P.; Teugels, E.; Umelo, I.A.; de Greve, J. Synergistic effect of afatinib with su11274 in non-small cell lung cancer cells resistant to gefitinib or erlotinib. PLoS One 2013, 8, e59708.

79. Seiwert, T.Y.; Jagadeeswaran, R.; Faoro, L.; Janamanchi, V.; Nallasura, V.; El Dinali, M.; Yala, S.; Kanteti, R.; Cohen, E.E.; Lingen, M.W.; et al. The met receptor tyrosine kinase is a potential novel therapeutic target for head and neck squamous cell carcinoma. Cancer Res. 2009, 69, 3021-3031. 
80. Zhang, Y.W.; Staal, B.; Essenburg, C.; Lewis, S.; Kaufman, D.; vande Woude, G.F. Strengthening context-dependent anticancer effects on non-small cell lung carcinoma by inhibition of both met and egfr. Mol. Cancer Ther. 2013, 12, 1429-1441.

81. Chen, Y.S.; Wang, J.T.; Chang, Y.F.; Liu, B.Y.; Wang, Y.P.; Sun, A.; Chiang, C.P. Expression of hepatocyte growth factor and c-met protein is significantly associated with the progression of oral squamous cell carcinoma in Taiwan. J. Oral. Pathol. Med. 2004, 33, 209-217.

82. Kim, C.H.; Moon, S.K.; Bae, J.H.; Lee, J.H.; Han, J.H.; Kim, K.; Choi, E.C. Expression of hepatocyte growth factor and c-met in hypopharyngeal squamous cell carcinoma. Acta Otolaryngol. 2006, 126, 88-94.

83. Marshall, D.D.; Kornberg, L.J. Overexpression of scatter factor and its receptor (c-met) in oral squamous cell carcinoma. Laryngoscope 1998, 108, 1413-1417.

84. Sawatsubashi, M.; Sasatomi, E.; Mizokami, H.; Tokunaga, O.; Shin, T. Expression of c-met in laryngeal carcinoma. Virchows Arch. 1998, 432, 331-335.

85. Knowles, L.M.; Stabile, L.P.; Egloff, A.M.; Rothstein, M.E.; Thomas, S.M.; Gubish, C.T.; Lerner, E.C.; Seethala, R.R.; Suzuki, S.; Quesnelle, K.M.; et al. Hgf and c-met participate in paracrine tumorigenic pathways in head and neck squamous cell cancer. Clin. Cancer Res. 2009, 15, 3740-3750.

86. Cortesina, G.; Martone, T.; Galeazzi, E.; Olivero, M.; de Stefani, A.; Bussi, M.; Valente, G.; Comoglio, P.M.; di Renzo, M.F. Staging of head and neck squamous cell carcinoma using the met oncogene product as marker of tumor cells in lymph node metastases. Int. J. Cancer 2000, 89, 286-292.

87. Galeazzi, E.; Olivero, M.; Gervasio, F.C.; de Stefani, A.; Valente, G.; Comoglio, P.M.; di Renzo, M.F.; Cortesina, G. Detection of met oncogene/hepatocyte growth factor receptor in lymph node metastases from head and neck squamous cell carcinomas. Eur. Arch. Otorhinolaryngol. 1997, 254, S138-S143.

88. Lo Muzio, L.; Leonardi, R.; Mignogna, M.D.; Pannone, G.; Rubini, C.; Pieramici, T.; Trevisiol, L.; Ferrari, F.; Serpico, R.; Testa, N.; et al. Scatter factor receptor (c-met) as possible prognostic factor in patients with oral squamous cell carcinoma. Anticancer Res. 2004, 24, 1063-1069.

89. Tuynman, J.B.; Lagarde, S.M.; Ten Kate, F.J.; Richel, D.J.; van Lanschot, J.J. Met expression is an independent prognostic risk factor in patients with oesophageal adenocarcinoma. $\mathrm{Br}$. J. Cancer 2008, 98, 1102-1108.

90. Aebersold, D.M.; Kollar, A.; Beer, K.T.; Laissue, J.; Greiner, R.H.; Djonov, V. Involvement of the hepatocyte growth factor/scatter factor receptor c-met and of bcl-xl in the resistance of oropharyngeal cancer to ionizing radiation. Int. J. Cancer 2001, 96, 41-54.

91. Akervall, J.; Guo, X.; Qian, C.N.; Schoumans, J.; Leeser, B.; Kort, E.; Cole, A.; Resau, J.; Bradford, C.; Carey, T.; et al. Genetic and expression profiles of squamous cell carcinoma of the head and neck correlate with cisplatin sensitivity and resistance in cell lines and patients. Clin. Cancer Res. 2004, 10, 8204-8213.

92. Ren, Y.; Cao, B.; Law, S.; Xie, Y.; Lee, P.Y.; Cheung, L.; Chen, Y.; Huang, X.; Chan, H.M.; Zhao, P.; et al. Hepatocyte growth factor promotes cancer cell migration and angiogenic factors expression: A prognostic marker of human esophageal squamous cell carcinomas. Clin. Cancer Res. 2005, 11, 6190-6197. 
93. Uchida, D.; Kawamata, H.; Omotehara, F.; Nakashiro, K.; Kimura-Yanagawa, T.; Hino, S.; Begum, N.M.; Hoque, M.O.; Yoshida, H.; Sato, M.; et al. Role of hgf/c-met system in invasion and metastasis of oral squamous cell carcinoma cells in vitro and its clinical significance. Int. J. Cancer 2001, 93, 489-496.

94. Hanzawa, M.; Shindoh, M.; Higashino, F.; Yasuda, M.; Inoue, N.; Hida, K.; Ono, M.; Kohgo, T.; Nakamura, M.; Notani, K.; et al. Hepatocyte growth factor upregulates elaf that induces oral squamous cell carcinoma cell invasion by activating matrix metalloproteinase genes. Carcinogenesis 2000, 21, 1079-1085.

95. Di Renzo, M.F.; Olivero, M.; Martone, T.; Maffe, A.; Maggiora, P.; Stefani, A.D.; Valente, G.; Giordano, S.; Cortesina, G.; Comoglio, P.M. Somatic mutations of the met oncogene are selected during metastatic spread of human hnsc carcinomas. Oncogene 2000, 19, 1547-1555.

96. Frixen, U.H.; Behrens, J.; Sachs, M.; Eberle, G.; Voss, B.; Warda, A.; Lochner, D.; Birchmeier, W. E-cadherin-mediated cell-cell adhesion prevents invasiveness of human carcinoma cells. J. Cell Biol. 1991, 113, 173-185.

97. Kim, C.H.; Kim, J.; Kahng, H.; Choi, E.C. Change of e-cadherin by hepatocyte growth factor and effects on the prognosis of hypopharyngeal carcinoma. Ann. Surg. Oncol. 2007, 14, 1565-1574.

98. Grotegut, S.; von Schweinitz, D.; Christofori, G.; Lehembre, F. Hepatocyte growth factor induces cell scattering through mapk/egr-1-mediated upregulation of snail. EMBO J. 2006, 25, 3534-3545.

99. Cano, A.; Perez-Moreno, M.A.; Rodrigo, I.; Locascio, A.; Blanco, M.J.; del Barrio, M.G.; Portillo, F.; Nieto, M.A. The transcription factor snail controls epithelial-mesenchymal transitions by repressing e-cadherin expression. Nat. Cell Biol. 2000, 2, 76-83.

100. Yokoyama, K.; Kamata, N.; Fujimoto, R.; Tsutsumi, S.; Tomonari, M.; Taki, M.; Hosokawa, H.; Nagayama, M. Increased invasion and matrix metalloproteinase-2 expression by snail-induced mesenchymal transition in squamous cell carcinomas. Int. J. Oncol. 2003, 22, 891-898.

101. Yokoyama, K.; Kamata, N.; Hayashi, E.; Hoteiya, T.; Ueda, N.; Fujimoto, R.; Nagayama, M. Reverse correlation of e-cadherin and snail expression in oral squamous cell carcinoma cells in vitro. Oral. Oncol. 2001, 37, 65-71.

102. Lim, Y.C.; Park, H.Y.; Hwang, H.S.; Kang, S.U.; Pyun, J.H.; Lee, M.H.; Choi, E.C.; Kim, C.H. (-)-epigallocatechin-3-gallate (egcg) inhibits hgf-induced invasion and metastasis in hypopharyngeal carcinoma cells. Cancer Lett. 2008, 271, 140-152.

103. Kitajo, H.; Shibata, T.; Nagayasu, H.; Kawano, T.; Hamada, J.; Yamashita, T.; Arisue, M. Rho regulates the hepatocyte growth factor/scatter factor-stimulated cell motility of human oral squamous cell carcinoma cells. Oncol. Rep. 2003, 10, 1351-1356.

104. Matsumoto, K.; Nakamura, T.; Kramer, R.H. Hepatocyte growth factor/scatter factor induces tyrosine phosphorylation of focal adhesion kinase (p125fak) and promotes migration and invasion by oral squamous cell carcinoma cells. J. Biol. Chem. 1994, 269, 31807-31813.

105. Zeng, Q.; Chen, S.; You, Z.; Yang, F.; Carey, T.E.; Saims, D.; Wang, C.Y. Hepatocyte growth factor inhibits anoikis in head and neck squamous cell carcinoma cells by activation of erk and akt signaling independent of nfkappa b. J. Biol. Chem. 2002, 277, 25203-25208. 
106. Dong, G.; Chen, Z.; Li, Z.Y.; Yeh, N.T.; Bancroft, C.C.; van Waes, C. Hepatocyte growth factor/scatter factor-induced activation of mek and pi3k signal pathways contributes to expression of proangiogenic cytokines interleukin-8 and vascular endothelial growth factor in head and neck squamous cell carcinoma. Cancer Res. 2001, 61, 5911-5918.

107. Dong, G.; Lee, T.L.; Yeh, N.T.; Geoghegan, J.; van Waes, C.; Chen, Z. Metastatic squamous cell carcinoma cells that overexpress c-met exhibit enhanced angiogenesis factor expression, scattering and metastasis in response to hepatocyte growth factor. Oncogene 2004, 23, 6199-6208.

108. Sun, S.; Wang, Z. Head neck squamous cell carcinoma c-met(+) cells display cancer stem cell properties and are responsible for cisplatin-resistance and metastasis. Int. J. Cancer 2011, 129, 2337-2348.

109. Rubin Grandis, J.; Melhem, M.F.; Barnes, E.L.; Tweardy, D.J. Quantitative immunohistochemical analysis of transforming growth factor-alpha and epidermal growth factor receptor in patients with squamous cell carcinoma of the head and neck. Cancer 1996, 78, 1284-1292.

110. Schmitz, S.; Machiels, J.P. Molecular biology of squamous cell carcinoma of the head and neck: Relevance and therapeutic implications. Expert Rev. Anticancer Ther. 2010, 10, 1471-1484.

111. Egloff, A.M.; Grandis, J.R. Targeting epidermal growth factor receptor and src pathways in head and neck cancer. Semin. Oncol. 2008, 35, 286-297.

112. Breindel, J.L.; Haskins, J.W.; Cowell, E.P.; Zhao, M.; Nguyen, D.X.; Stern, D.F. Egf receptor activates met through mapk to enhance non-small cell lung carcinoma invasion and brain metastasis. Cancer Res. 2013, 73, 5053-5065.

113. Burtness, B.; Bauman, J.E.; Galloway, T. Novel targets in hpv-negative head and neck cancer: Overcoming resistance to egfr inhibition. Lancet Oncol. 2013, 14, e302-e309.

114. Timpson, P.; Wilson, A.S.; Lehrbach, G.M.; Sutherland, R.L.; Musgrove, E.A.; Daly, R.J. Aberrant expression of cortactin in head and neck squamous cell carcinoma cells is associated with enhanced cell proliferation and resistance to the epidermal growth factor receptor inhibitor gefitinib. Cancer Res. 2007, 67, 9304-9314.

115. Stabile, L.P.; He, G.; Lui, V.W.; Thomas, S.; Henry, C.; Gubish, C.T.; Joyce, S.; Quesnelle, K.M.; Siegfried, J.M.; Grandis, J.R. C-src activation mediates erlotinib resistance in head and neck cancer by stimulating c-met. Clin. Cancer Res. 2013, 19, 380-392.

116. Date, K.; Matsumoto, K.; Shimura, H.; Tanaka, M.; Nakamura, T. Hgf/nk4 is a specific antagonist for pleiotrophic actions of hepatocyte growth factor. FEBS Lett. 1997, 420, 1-6.

117. Matsumoto, K.; Nakamura, T. Mechanisms and significance of bifunctional nk4 in cancer treatment. Biochem. Biophys. Res. Commun. 2005, 333, 316-327.

118. Mizuno, S.; Nakamura, T. Hgf-met cascade, a key target for inhibiting cancer metastasis: The impact of nk4 discovery on cancer biology and therapeutics. Int. J. Mol. Sci. 2013, 14, 888-919.

119. Burgess, T.; Coxon, A.; Meyer, S.; Sun, J.; Rex, K.; Tsuruda, T.; Chen, Q.; Ho, S.Y.; Li, L.; Kaufman, S.; et al. Fully human monoclonal antibodies to hepatocyte growth factor with therapeutic potential against hepatocyte growth factor/c-met-dependent human tumors. Cancer Res. 2006, 66, 1721-1729.

120. Kakkar, T.; Ma, M.; Zhuang, Y.; Patton, A.; Hu, Z.; Mounho, B. Pharmacokinetics and safety of a fully human hepatocyte growth factor antibody, amg 102, in cynomolgus monkeys. Pharm. Res. 2007, 24, 1910-1918. 
121. Rosen, P.J.; Sweeney, C.J.; Park, D.J.; Beaupre, D.M.; Deng, H.; Leitch, I.M.; Shubhakar, P.; Zhu, M.; Oliner, K.S.; Anderson, A.; et al. A phase ib study of amg 102 in combination with bevacizumab or motesanib in patients with advanced solid tumors. Clin. Cancer Res. 2010, 16, 2677-2687.

122. Wen, P.Y.; Schiff, D.; Cloughesy, T.F.; Raizer, J.J.; Laterra, J.; Smitt, M.; Wolf, M.; Oliner, K.S.; Anderson, A.; Zhu, M.; et al. A phase ii study evaluating the efficacy and safety of amg 102 (rilotumumab) in patients with recurrent glioblastoma. Neurooncology 2011, 13, 437-446.

123. Scagliotti, G.V.; Novello, S.; von Pawel, J. The emerging role of met/hgf inhibitors in oncology. Cancer Treat. Rev. 2013, 39, 793-801.

124. Jin, H.; Yang, R.; Zheng, Z.; Romero, M.; Ross, J.; Bou-Reslan, H.; Carano, R.A.; Kasman, I.; Mai, E.; Young, J.; et al. Metmab, the one-armed 5d5 anti-c-met antibody, inhibits orthotopic pancreatic tumor growth and improves survival. Cancer Res. 2008, 68, 4360-4368.

125. Martens, T.; Schmidt, N.O.; Eckerich, C.; Fillbrandt, R.; Merchant, M.; Schwall, R.; Westphal, M.; Lamszus, K. A novel one-armed anti-c-met antibody inhibits glioblastoma growth in vivo. Clin. Cancer Res. 2006, 12, 6144-6152.

126. Munshi, N.; Jeay, S.; Li, Y.; Chen, C.R.; France, D.S.; Ashwell, M.A.; Hill, J.; Moussa, M.M.; Leggett, D.S.; Li, C.J. Arq 197, a novel and selective inhibitor of the human c-met receptor tyrosine kinase with antitumor activity. Mol. Cancer Ther. 2010, 9, 1544-1553.

127. Bagai, R.; Fan, W.; Ma, P.C. Arq-197, an oral small-molecule inhibitor of c-met for the treatment of solid tumors. IDrugs 2010, 13, 404-414.

128. Eder, J.P.; vande Woude, G.F.; Boerner, S.A.; LoRusso, P.M. Novel therapeutic inhibitors of the c-met signaling pathway in cancer. Clin. Cancer Res. 2009, 15, 2207-2214.

129. Christensen, J.G.; Zou, H.Y.; Arango, M.E.; Li, Q.; Lee, J.H.; McDonnell, S.R.; Yamazaki, S.; Alton, G.R.; Mroczkowski, B.; Los, G. Cytoreductive antitumor activity of pf-2341066, a novel inhibitor of anaplastic lymphoma kinase and c-met, in experimental models of anaplastic large-cell lymphoma. Mol. Cancer Ther. 2007, 6, 3314-3322.

130. Xu, H.; Stabile, L.P.; Gubish, C.T.; Gooding, W.E.; Grandis, J.R.; Siegfried, J.M. Dual blockade of egfr and c-met abrogates redundant signaling and proliferation in head and neck carcinoma cells. Clin. Cancer Res. 2011, 17, 4425-4438.

131. Qian, F.; Engst, S.; Yamaguchi, K.; Yu, P.; Won, K.A.; Mock, L.; Lou, T.; Tan, J.; Li, C.; Tam, D.; et al. Inhibition of tumor cell growth, invasion, and metastasis by exel-2880 (x1880, gsk1363089), a novel inhibitor of hgf and vegf receptor tyrosine kinases. Cancer Res. 2009, 69, 8009-8016.

132. Yan, S.B.; Peek, V.L.; Ajamie, R.; Buchanan, S.G.; Graff, J.R.; Heidler, S.A.; Hui, Y.H.; Huss, K.L.; Konicek, B.W.; Manro, J.R.; et al. Ly2801653 is an orally bioavailable multi-kinase inhibitor with potent activity against met, mst1r, and other oncoproteins, and displays anti-tumor activities in mouse xenograft models. Invest. New Drugs 2013, 31, 833-844.

(C) 2013 by the authors; licensee MDPI, Basel, Switzerland. This article is an open access article distributed under the terms and conditions of the Creative Commons Attribution license (http://creativecommons.org/licenses/by/3.0/). 